Supporting Information for

\title{
Electronic Anisotropy and Superconductivity in One-Dimensional Electride
}

\section{$\mathrm{Ca}_{3} \mathrm{Si}$}

Baisheng Sa ${ }^{1}$, Rui Xiong ${ }^{1}$, Cuilian Wen ${ }^{1, *}$, Yan-Ling Li ${ }^{2, * *}$, Peng Lin ${ }^{1}$, Qilang Lin ${ }^{1}$, Masakazu Anpo ${ }^{3}$ and Zhimei Sun ${ }^{4, * * *}$

${ }^{1}$ Key Laboratory of Eco-materials Advanced Technology, College of Materials Science and Engineering, Fuzhou University, Fuzhou 350100, P. R. China

${ }^{2}$ School of Physics and Electronic Engineering, Jiangsu Normal University, 221116, Xuzhou, P. R. China

${ }^{3}$ State Key Laboratory of Photocatalysis on Energy and Environment, Fuzhou University, Fuzhou 350116, P. R. China

${ }^{4}$ School of Materials Science and Engineering, and Center for Integrated Computational Materials Engineering, International Research Institute for Multidisciplinary Science, Beihang University, 100191 Beijing, P. R. China

Corresponding authors:

*Corresponding author: clwen@fzu.edu.cn.

**Corresponding author: ylli@jsnu.edu.cn.

***Corresponding author: zmsun@buaa.edu.cn. 


\section{Crystal structures of predicted $\mathrm{Ca}_{3} \mathrm{Si}$ compounds at ambient condition}

At the ambient condition, our results show that the hexagonal $P 6_{3} / m m c \mathrm{Ca}_{3} \mathrm{Si}$ with the lattice parameters of $a=b=6.963 \AA, c=5.333 \AA$ and the volume about $223.930 \AA^{3}$, the orthorhombic $I 4 / \mathrm{mcm}$ structure with the lattice parameters about $a=b$ $=6.887 \AA, c=9.878 \AA$ and the volume about $468.450 \AA^{3}$, and the monoclinic $C 2 / c$ structure with the lattice parameters of $a=12.070 \AA, b=6.955 \AA, c=9.930 \AA$ and the volume about $475.450 \AA^{3}$. It is obvious that the lattice constants and the volumes of all the predicted phases decrease gradually with the increasing external pressure over the whole positive pressure range. 
Table S1. The atomic Wyckoff positions for $P 6_{3} / m m c \mathrm{Ca}_{3} \mathrm{Si}$ at different pressures

\begin{tabular}{cccccc}
\hline $\begin{array}{c}\text { Pressure } \\
(\mathrm{GPa})\end{array}$ & Atom & Site & $\mathrm{x}$ & $\mathrm{y}$ & $\mathrm{z}$ \\
\hline \multirow{2}{*}{0} & Ca1 & 6h & 0.82420 & 0.64840 & 0.25000 \\
& Si1 & 2c & 0.33333 & 0.66667 & 0.25000 \\
& Ca1 & 6h & 0.82488 & 0.64976 & 0.25000 \\
10 & Si1 & 2c & 0.33333 & 0.66667 & 0.25000 \\
& Ca1 & 6h & 0.82495 & 0.64990 & 0.25000 \\
20 & Si1 & 2c & 0.33333 & 0.66667 & 0.25000 \\
& Ca1 & 6h & 0.82498 & 0.64995 & 0.25000 \\
30 & Si1 & 2c & 0.33333 & 0.66667 & 0.25000 \\
\hline
\end{tabular}

Table S2. The atomic Wyckoff positions for $I 4 / m c m \mathrm{Ca}_{3} \mathrm{Si}$ at different pressures

\begin{tabular}{cccccc}
\hline $\begin{array}{c}\text { Pressure } \\
(\mathrm{GPa})\end{array}$ & Atom & Site & $\mathrm{x}$ & $\mathrm{y}$ & $\mathrm{z}$ \\
\hline \multirow{4}{*}{0} & $\mathrm{Ca} 1$ & $8 \mathrm{~h}$ & 0.69011 & 0.19011 & 0.00000 \\
& $\mathrm{Ca} 2$ & $4 \mathrm{a}$ & 0.00000 & 0.00000 & 0.25000 \\
& $\mathrm{Si} 1$ & $4 \mathrm{~b}$ & 0.00000 & 0.50000 & 0.25000 \\
& $\mathrm{Ca} 1$ & $8 \mathrm{~h}$ & 0.71576 & 0.21576 & 0.00000 \\
10 & $\mathrm{Ca} 2$ & $4 \mathrm{a}$ & 0.00000 & 0.00000 & 0.25000 \\
& $\mathrm{Si} 1$ & $4 \mathrm{~b}$ & 0.00000 & 0.50000 & 0.25000 \\
& $\mathrm{Ca} 1$ & $8 \mathrm{~h}$ & 0.74717 & 0.24717 & 0.00000 \\
20 & $\mathrm{Ca} 2$ & $4 \mathrm{a}$ & 0.00000 & 0.00000 & 0.25000 \\
& $\mathrm{Si} 1$ & $4 \mathrm{~b}$ & 0.00000 & 0.50000 & 0.25000 \\
& $\mathrm{Ca} 1$ & $8 \mathrm{~h}$ & 0.74998 & 0.24998 & 0.00000 \\
30 & $\mathrm{Ca} 2$ & $4 \mathrm{a}$ & 0.00000 & 0.00000 & 0.25000 \\
& $\mathrm{Si} 1$ & $4 \mathrm{~b}$ & 0.00000 & 0.50000 & 0.25000 \\
\hline
\end{tabular}

Table S3. The atomic Wyckoff positions for $C 2 / c \mathrm{Ca}_{3} \mathrm{Si}$ at different pressures

\begin{tabular}{cccccc}
\hline $\begin{array}{c}\text { Pressure } \\
(\mathrm{GPa})\end{array}$ & Atom & Site & $\mathrm{x}$ & $\mathrm{y}$ & $\mathrm{z}$ \\
\hline \multirow{3}{*}{0} & $\mathrm{Ca} 1$ & $8 \mathrm{f}$ & 0.20046 & 0.49890 & 0.30086 \\
& $\mathrm{Ca} 2$ & $4 \mathrm{e}$ & 0.00000 & 0.15877 & 0.25000 \\
& $\mathrm{Si} 1$ & $4 \mathrm{e}$ & 0.00000 & 0.73556 & 0.25000 \\
\hline \multirow{4}{*}{10} & $\mathrm{Ca} 1$ & $8 \mathrm{f}$ & 0.22459 & 0.49929 & 0.27629 \\
& $\mathrm{Ca} 2$ & $4 \mathrm{e}$ & 0.00000 & 0.20009 & 0.25000 \\
& $\mathrm{Si} 1$ & $4 \mathrm{e}$ & 0.00000 & 0.74885 & 0.25000 \\
\hline \multirow{3}{*}{20} & $\mathrm{Ca} 1$ & $8 \mathrm{f}$ & 0.74850 & 0.00183 & 0.24971 \\
& $\mathrm{Ca} 2$ & $4 \mathrm{e}$ & 0.00000 & 0.24702 & 0.25000 \\
& $\mathrm{Si} 1$ & $4 \mathrm{e}$ & 0.00000 & 0.75005 & 0.25000 \\
\hline \multirow{3}{*}{30} & $\mathrm{Ca} 1$ & $8 \mathrm{f}$ & 0.74997 & 0.00011 & 0.24992 \\
& $\mathrm{Ca} 2$ & $4 \mathrm{e}$ & 0.00000 & 0.24994 & 0.25000 \\
& $\mathrm{Si} 1$ & $4 \mathrm{e}$ & 0.00000 & 0.75000 & 0.25000 \\
\hline
\end{tabular}


(a)

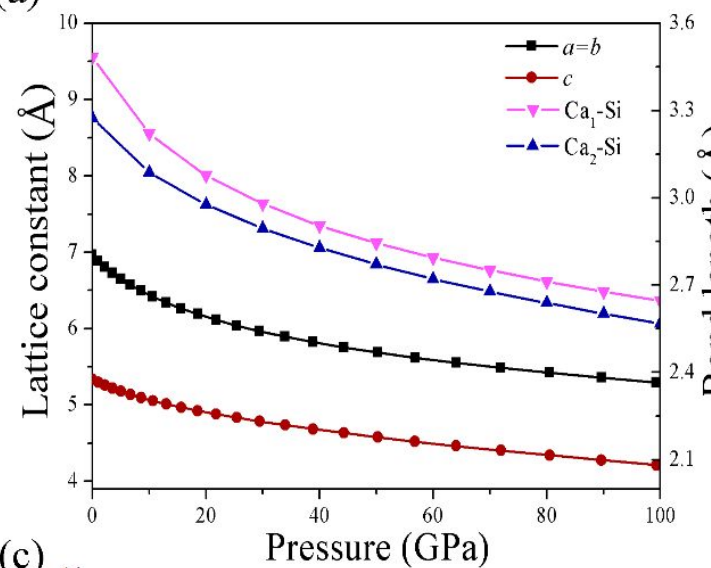

(c)

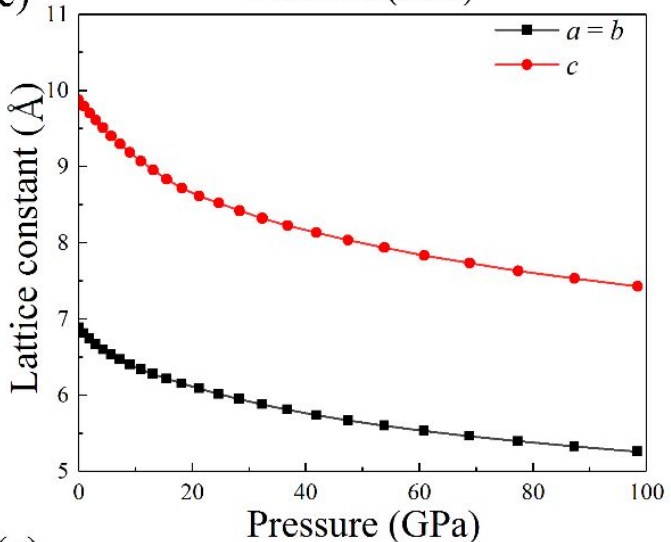

(e)

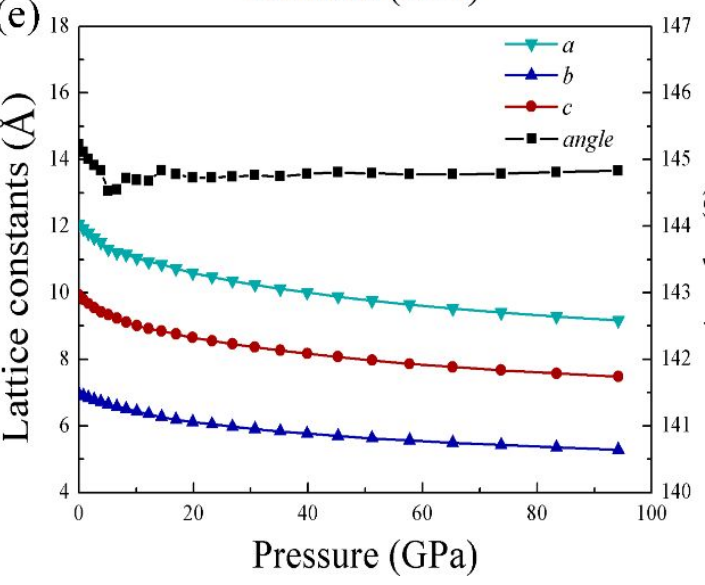

(b)

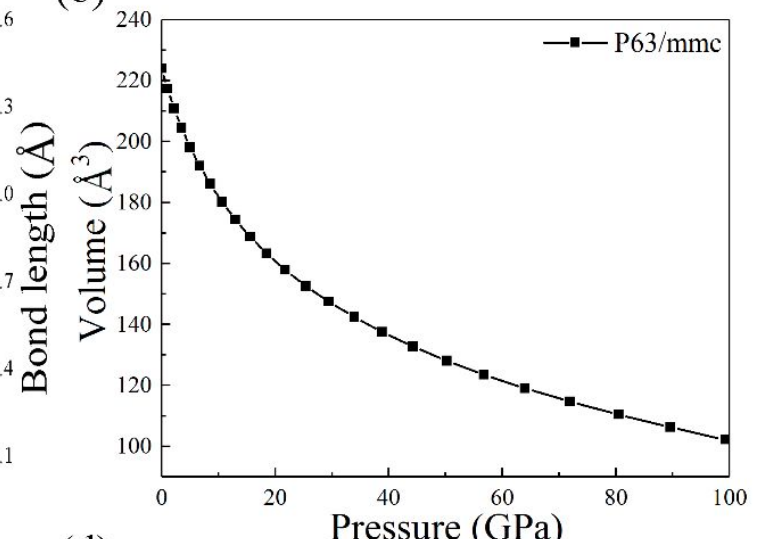

(d)
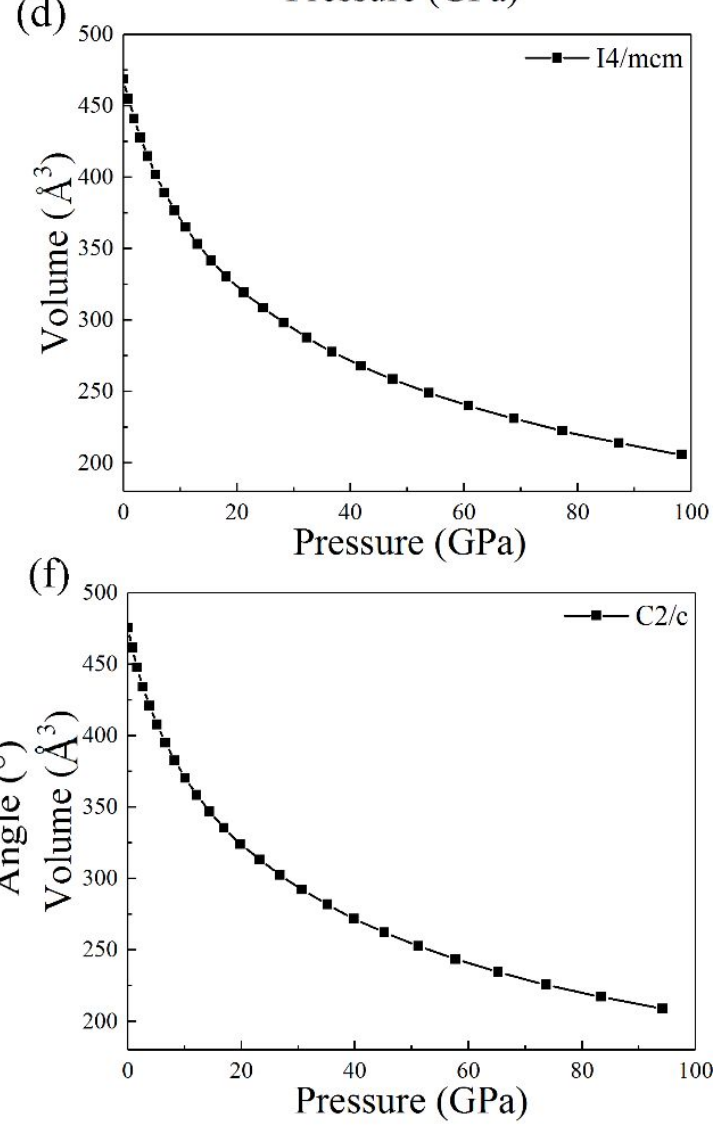

Fig. S1. The (a) lattice constants and (b) volume of $\mathrm{Pb}_{3} / m m c \mathrm{Ca}_{3} \mathrm{Si}$ at different pressure. The (c) lattice constants and (d) volume of $I 4 / \mathrm{mcm} \mathrm{Ca}_{3} \mathrm{Si}$ at different pressure. The (e) lattice constants and (f) volume of $C 2 / c \mathrm{Ca}_{3} \mathrm{Si}$ at different pressure. 


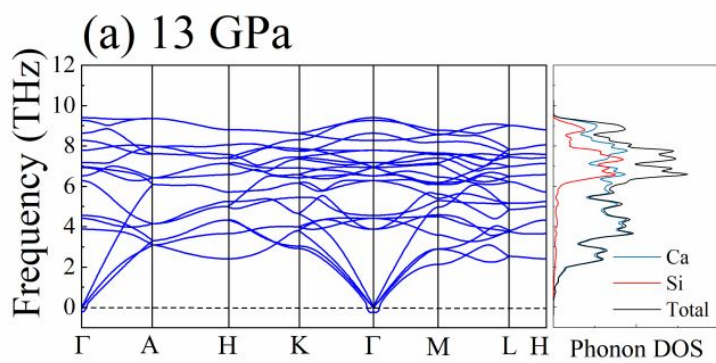

(b) $13.5 \mathrm{GPa}$

(c) $30 \mathrm{GPa}$

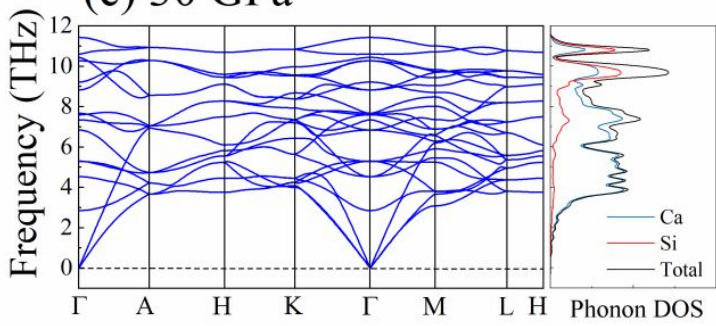

(d) $60 \mathrm{GPa}$

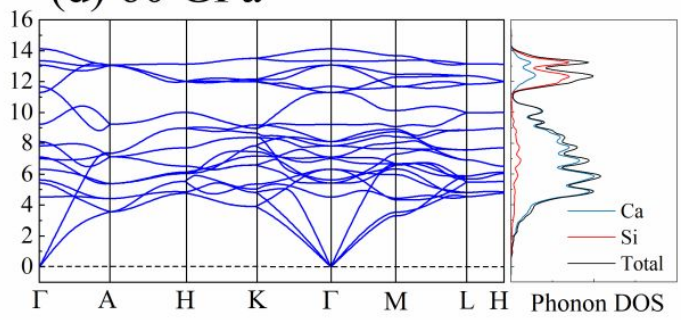

(e) $80 \mathrm{GPa}$

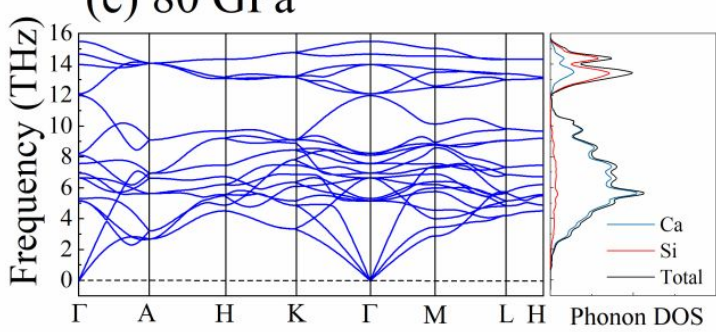

(f) $100 \mathrm{GPa}$

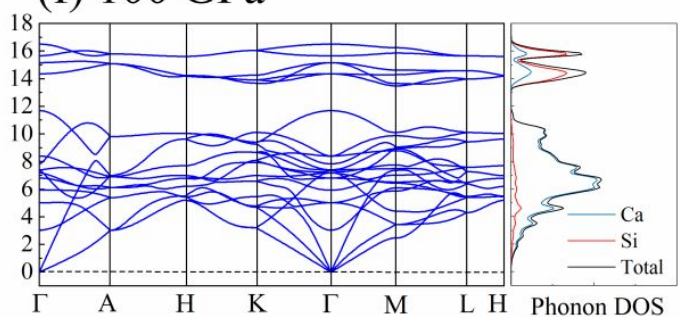

(g) $104 \mathrm{GPa}$

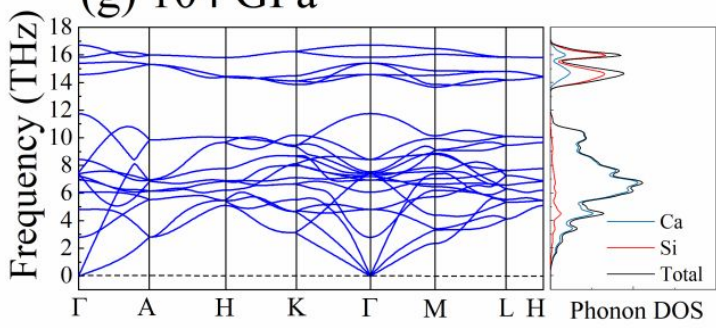

(h) $105 \mathrm{GPa}$

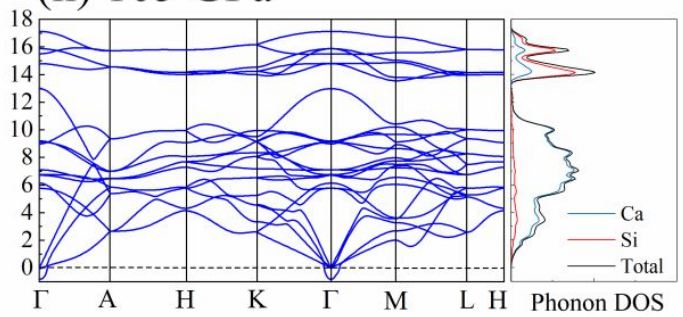

Fig. S2. The phonon dispersion curves and phonon density of states for $P 6_{3} / m m c$ $\mathrm{Ca}_{3} \mathrm{Si}$ at (a) $13 \mathrm{GPa}$, (b) $13.5 \mathrm{GPa}$, (c) $30 \mathrm{GPa}$, (d) $60 \mathrm{GPa}$, (e) $80 \mathrm{GPa}$ and (f) 100 $\mathrm{GPa}$, respectively. 
(a) $30 \mathrm{GPa}$

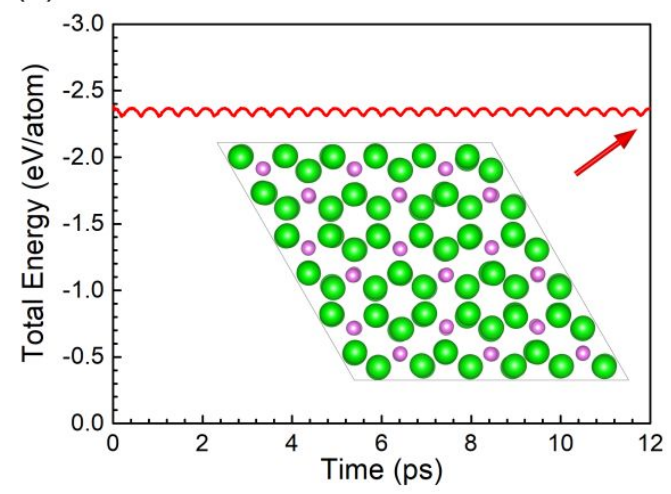

(c) $30 \mathrm{GPa}$

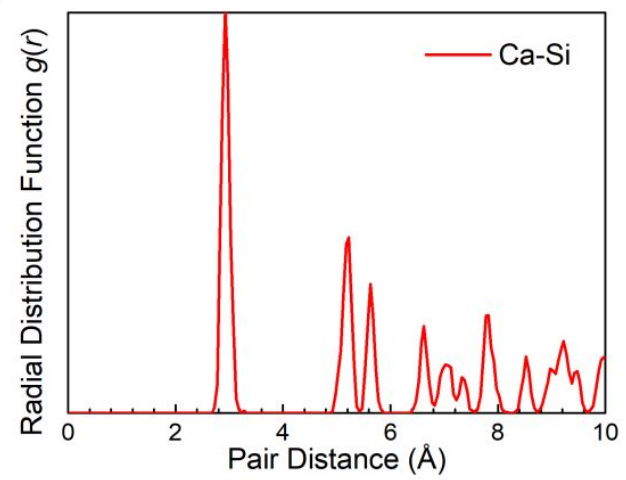

(b) $100 \mathrm{GPa}$

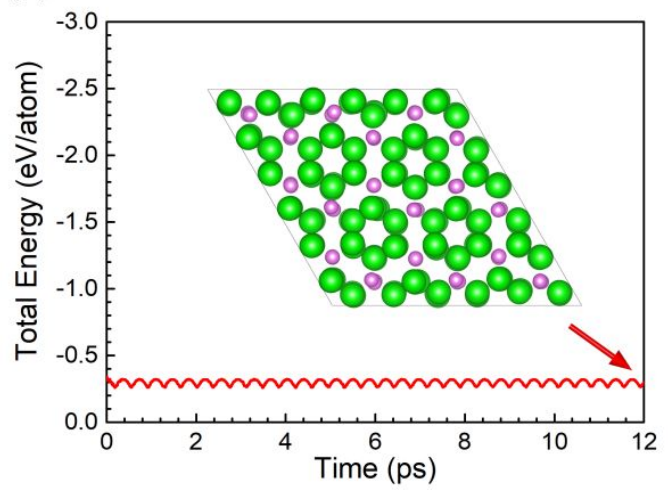

(d) $100 \mathrm{GPa}$

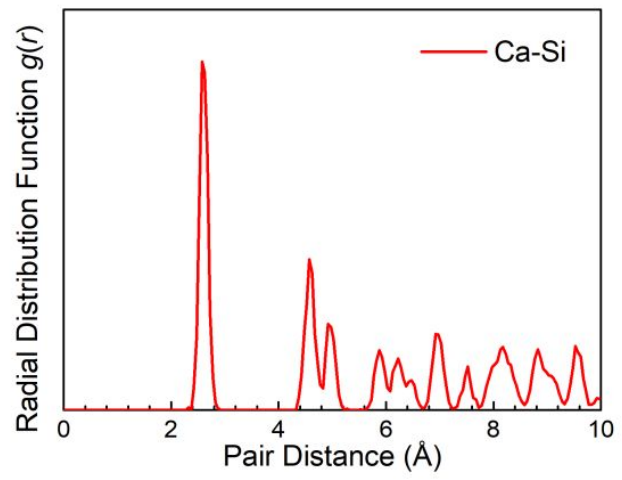

Fig. S3. The total energy evolution and structure snapshots from AIMD simulations after $12 \mathrm{ps}$ annealing at $300 \mathrm{~K}$ for $\mathrm{P}_{3} / \mathrm{mmc} \mathrm{Ca}_{3} \mathrm{Si}$ at (a) $30 \mathrm{GPa}$ and (b) $100 \mathrm{GPa}$. The normalized radial distribution function $g(r)$ after 12 ps annealing at $300 \mathrm{~K}$ for $\mathrm{Pb}_{3} / \mathrm{mmc} \mathrm{Ca}_{3} \mathrm{Si}$ at (c) $30 \mathrm{GPa}$ and (d) $100 \mathrm{GPa}$. 


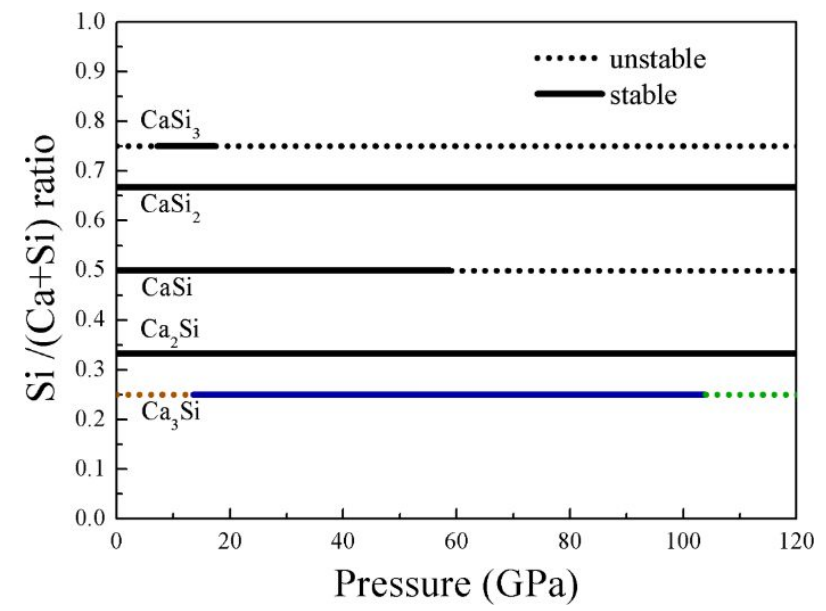

Fig. S4. The Ca-Si phase stability ranges as a function of pressure. 


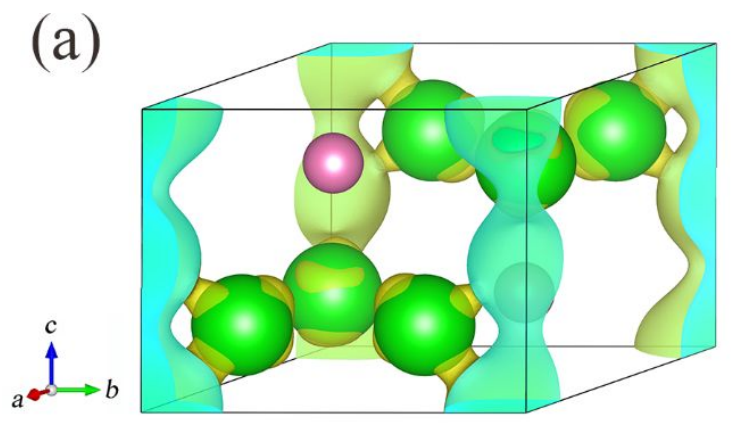

(b)

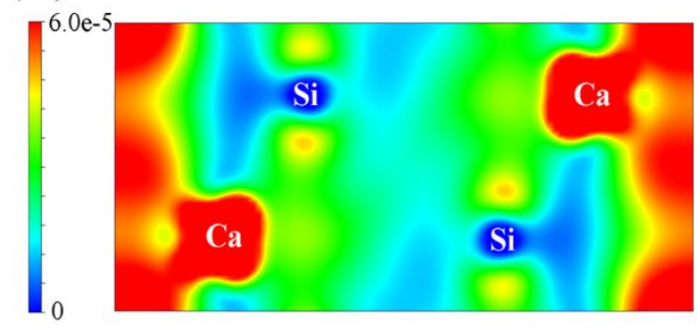

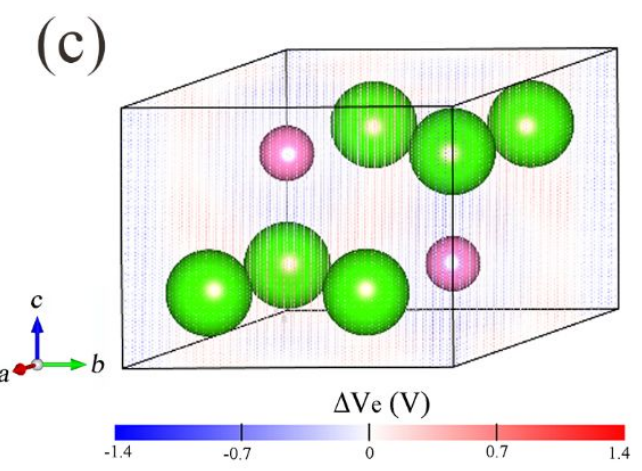

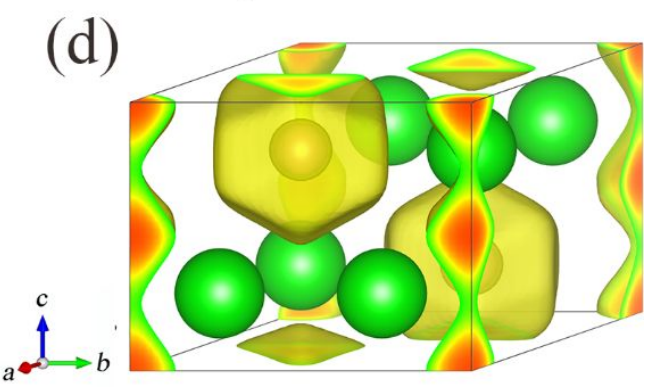

Fig. S5. The decomposed charge density around the Fermi level $\left(-0.5 \mathrm{eV}<\mathrm{E}_{\mathrm{F}}<0 \mathrm{eV}\right)$ (a) with an isosurface value of $5 \times 10^{-5} \mathrm{e} / \mathrm{A}^{3}$ and (b) its $2 \mathrm{D}$ plot in the (110) plane of $P 6_{3} / m m c \mathrm{Ca}_{3} \mathrm{Si}$ at $30 \mathrm{GPa}$. (c) The density plot of the electrostatic difference potential of $P 6_{3} / m m c \mathrm{Ca}_{3} \mathrm{Si}$ at $30 \mathrm{GPa}$. (d) The ELF of $P 6_{3} / m m c \mathrm{Ca}_{3} \mathrm{Si}$ at $30 \mathrm{GPa}$ with an isosurface value of 0.5 . 
(a) $13.5 \mathrm{GPa}$

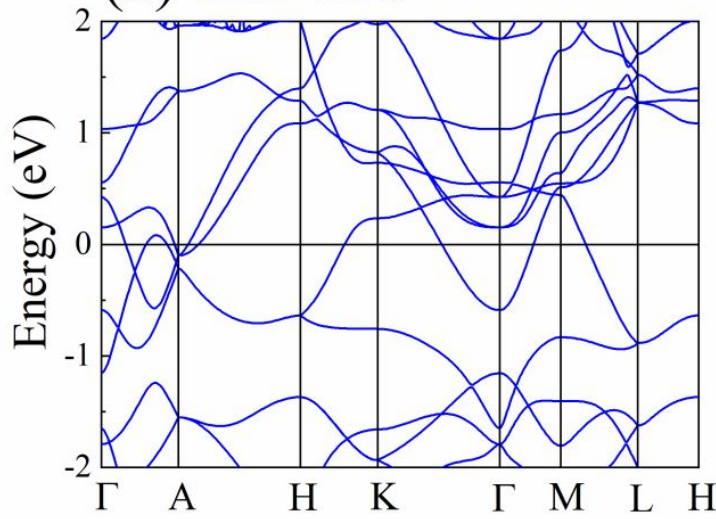

(c) $30 \mathrm{GPa}$

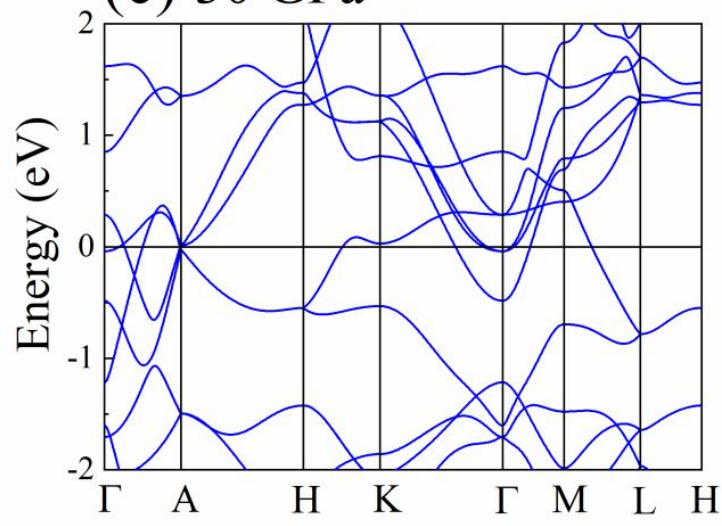

(e) $80 \mathrm{GPa}$

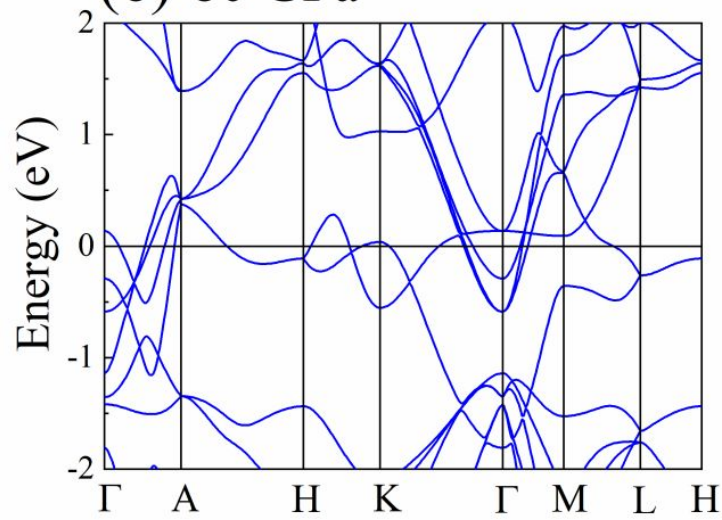

(b) $20 \mathrm{GPa}$

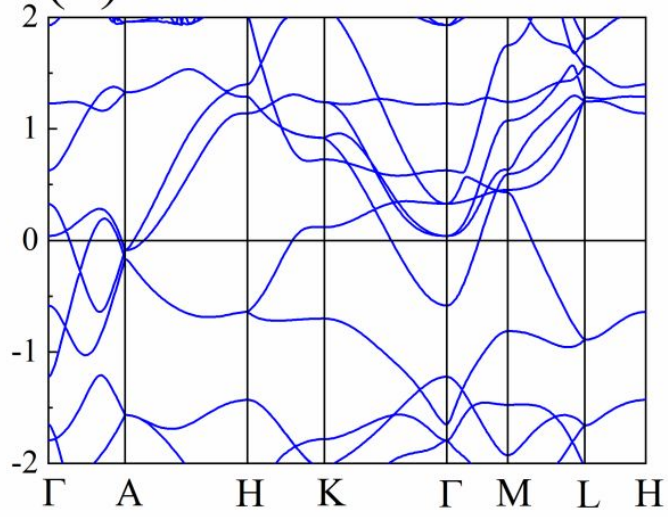

(d) $60 \mathrm{GPa}$

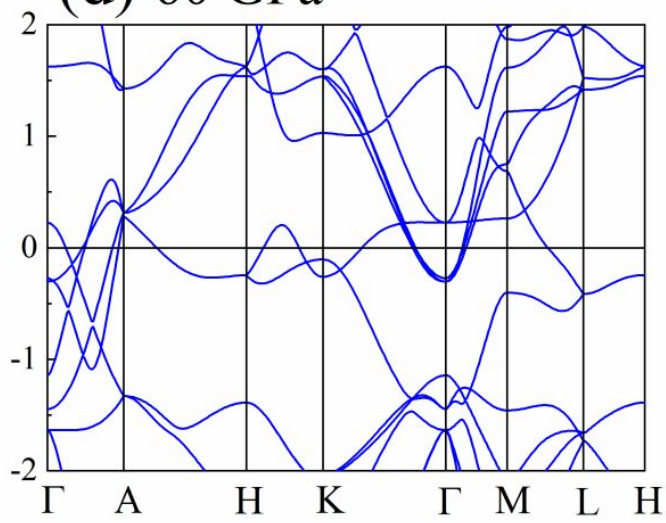

(f) $100 \mathrm{GPa}$

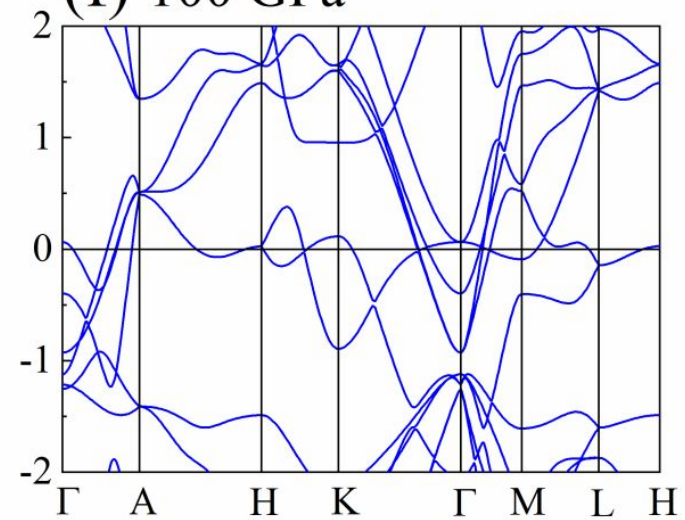

Fig. S6. The band structure of $P 6_{3} / m m c \mathrm{Ca}_{3} \mathrm{Si}$ at (a) $13.5 \mathrm{GPa}$, (b) $20 \mathrm{GPa}$, (c) $30 \mathrm{GPa}$, (d) $60 \mathrm{GPa}$, (e) $80 \mathrm{GPa}$ and (f) $100 \mathrm{GPa}$, respectively. 
(a) $13.5 \mathrm{GPa}$
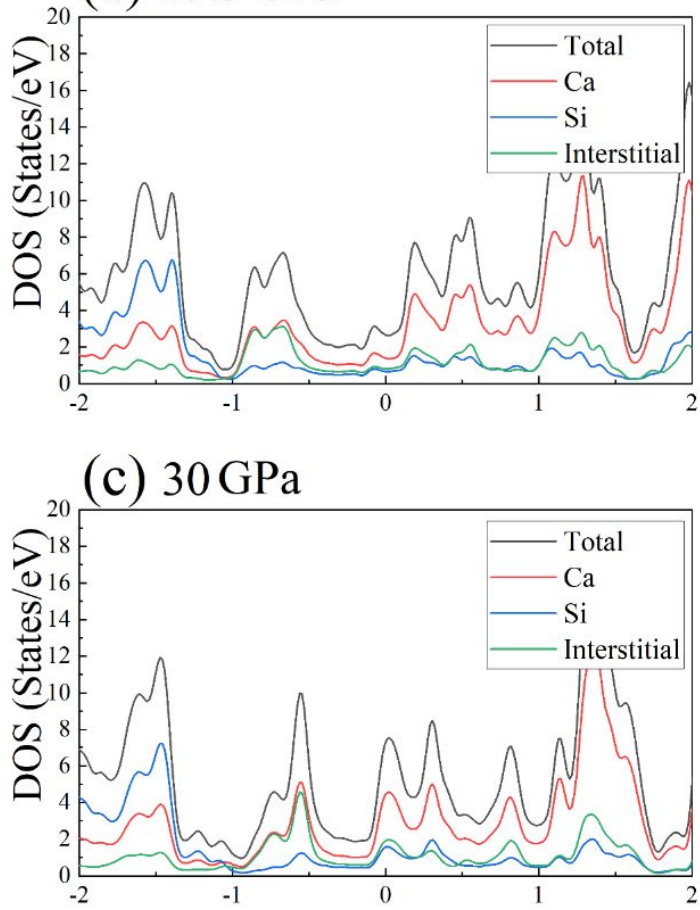

(e) $80 \mathrm{GPa}$

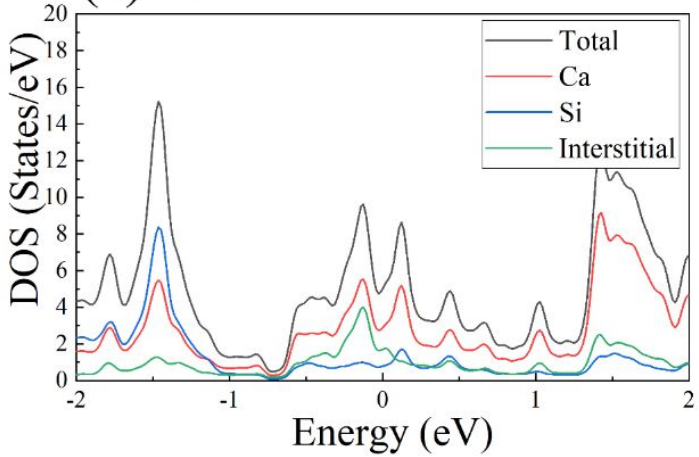

(b) $20 \mathrm{GPa}$

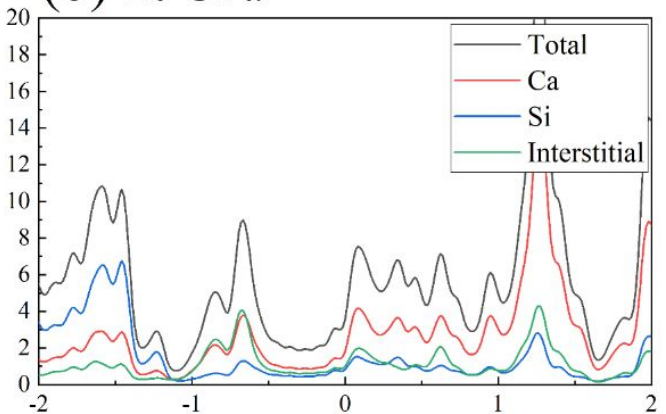

(d) $60 \mathrm{GPa}$

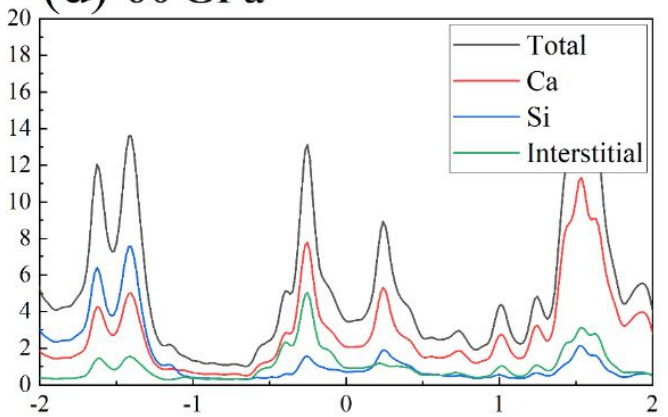

(f) $100 \mathrm{GPa}$

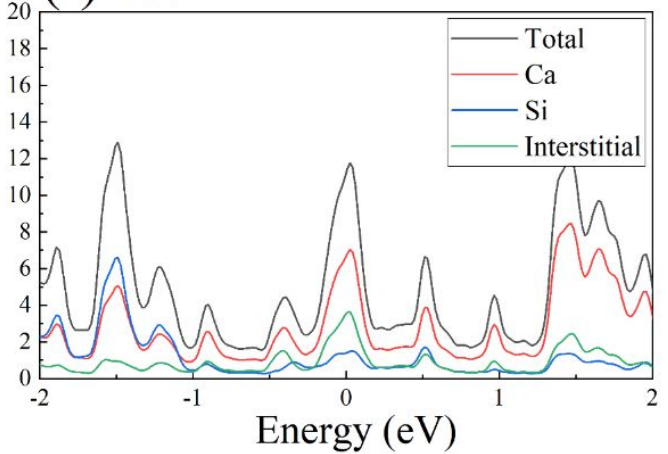

Fig. S7. The density of states of $P 6_{3} / m m c \mathrm{Ca}_{3} \mathrm{Si}$ at (a) $13.5 \mathrm{GPa}$, (b) $20 \mathrm{GPa}$, (c) 30 $\mathrm{GPa}$, (d) $60 \mathrm{GPa}$, (e) $80 \mathrm{GPa}$ and (f) $100 \mathrm{GPa}$, respectively. 

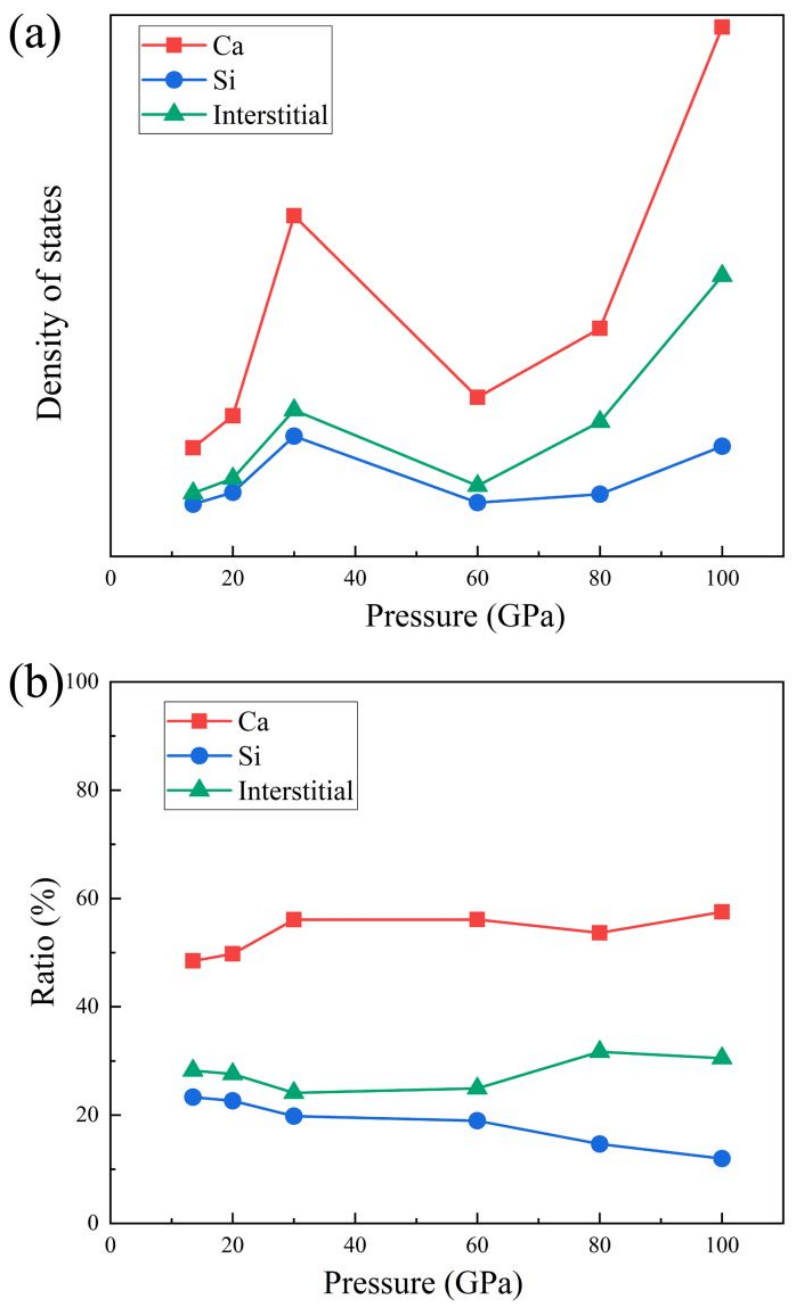

Fig. S8. (a) The density of states and (b) corresponding contribution ration at Fermi level of $\mathrm{P}_{3} / \mathrm{mmc} \mathrm{Ca}_{3} \mathrm{Si}$ as a functional of pressure. 